\title{
CHANGES IN THE HUMAN TRANSCRIPTOME UPON VITAMIN D SUPPLEMENTATION
}

Yvonne Pasing ${ }^{1,2}$, Christopher Graham Fenton ${ }^{3,4}$, Rolf Jorde ${ }^{1,2}$ and Ruth Hracky Paulssen ${ }^{3,4}$

${ }^{1}$ Tromsø Endocrine Research Group, Department of Clinical Medicine, Faculty of Health Sciences, UiT - The Arctic University of Norway, Tromsø, Norway 9037

${ }^{2}$ Division of Internal Medicine, University Hospital of North Norway, Tromsø, Norway

${ }^{3}$ Genomics Support Center Tromsø (GSCT), Department of Clinical Medicine, Faculty of Health Sciences, UiT - The Arctic University of Norway, Tromsø, Norway 9037

${ }^{4}$ Gastroenterology and Nutrition Research Group, Department of Clinical Medicine, Faculty of Health Sciences, UiT - The Arctiv University of Norway, Tromsø, Norway 9037

Corresponding author:

Yvonne Pasing, Department of Clinical Medicine, Faculty of Health Sciences, UiT - The Arctic University of Norway, NO-9037 Tromsø, Norway, E-Mail: yvonne.pasing@uit.no

Keywords: Apoptosis, gene expression, fertility, immune system, oxidative stress, vitamin D

\author{
Abbreviations: \\ GSEA - Gene Set Enrichment Analysis \\ 1,25(OH $)_{2} \mathrm{D}$ - 1,25-dihydroxyvitamin D \\ 25(OH)D - 25-hydroxyvitamin D \\ PANTHER - Protein Analysis through Evolutionary Relationships \\ PCA - Principal component analysis \\ PLS - Partial least square regression analysis \\ RCT - Randomized controlled trial \\ VDR - Vitamin D receptor
}

Highlights:

- Gene expression analysis of 94 subject after long term RCT

- Stronger effect of supplementation on the gene expression in women

- Connection between vitamin D level and gene regulation

- Influence of vitamin D on immune system, oxidative stress, apoptosis and reproduction

- 72 novel genes influenced by vitamin D were identified 


\begin{abstract}
Vitamin D is hydroxylated in the liver and kidneys to its active form, which can bind to the vitamin D receptor (VDR). The VDR is present in a wide variety of different cells types and tissues and acts as a transcription factor. Although activation of the VDR is estimated to regulate expression of up to $5 \%$ of the human genome, our study is the first analysing gene expression after supplementation in more than 10 subjects.

Subjects of a randomized controlled trial (RCT) received either vitamin $D_{3}(n=47)$ in a weekly dose of 20,000 IU or placebo $(n=47)$ for a period of three to five years. For this study, blood samples for preparation of RNA were drawn from the subjects and mRNA gene expression in blood was determined using microarray analysis.

The two study groups were similar regarding gender, age, BMI and duration of supplementation, whereas the mean serum 25-hydroxyvitamin D (25(OH)D) level as expected was significantly higher in the vitamin D group (119 versus $63 \mathrm{nmol} / \mathrm{L}$ ). When analysing all subjects, nearly no significant differences in gene expression between the two groups were found. However, when analysing men and women separately, significant effects on gene expression were observed for women. Furthermore, when only including subjects with the highest and lowest serum 25(OH)D levels, additional vitamin D regulated genes were disclosed. Thus, a total of 99 genes $(p<0.05$, log 2 fold change $\geq|0.2|)$ were found to be regulated, of which 72 have not been published before as influenced by vitamin $\mathrm{D}$. These genes were particularly involved in the interleukin signalling pathway, oxidative stress response, apoptosis signalling pathway and gonadotropin releasing hormone receptor pathway. Thus, our results open the possibility for many future studies.
\end{abstract}




\section{Introduction}

Vitamin D is fat-soluble and generated in the skin upon UV-radiation, but can also be obtained through the diet. It is well established that vitamin D plays a major role in calcium homeostasis and bone mineralization, and that insufficient vitamin D intake can lead to skeletal diseases like rickets in children and osteomalacia in adults [1]. Several cross-sectional studies have found correlations between vitamin D deficiency and autoimmune diseases, different cancer types, infections, cardiovascular diseases, depression, mortality and obesity [2-7]. Nevertheless, the role and functions of vitamin D in the human body are not yet fully understood [8]. Vitamin D insufficiency or deficiency is estimated to be a widespread pandemic [9] affecting approximately $40 \%$ of the European population [10]. However, these data are of very variable quality hence estimations might by highly biased [11].

After generation in the skin upon UV-radiation, vitamin D is hydroxylated in the liver to 25hydroxyvitamin D (25(OH)D), which is the storage form of vitamin D and target for analyzing a person's vitamin D status. Next to diet and sun exposure, adiposity, age, skin colour, genetic and epigenetic factors account for differences in 25(OH)D levels [12]. 25(OH)D is further hydroxylated in the kidneys to its active form 1,25-dihydroxyvitamin $\mathrm{D}\left(1,25(\mathrm{OH})_{2} \mathrm{D}\right)$, which can bind to the vitamin D receptor (VDR). Due to its lipophilic character, $1,25(\mathrm{OH})_{2} \mathrm{D}$ is able to pass through biological membranes, hence gene regulation by vitamin $\mathrm{D}$ does not require additional signal transduction steps as those known for hydrophilic signalling molecules, such as peptide hormones, growth factors and cytokines [13].

The VDR is present in a wide variety of different cells types and tissues, and is a member of the nuclear receptor superfamily, known to modulate gene expression by oscillating between on and off states. VDR acts as a transcription factor and its activation is estimated to regulate expression of up to $5 \%$ of the human genome [14], with more than 200 genes estimated to be primary vitamin D targets [15]. Depending on the presence or absence of its ligand, the VDR does not only activate but can also repress gene transcription [16]. Effects of the VDR actions on cell cycling, regulation of growth, proliferation, differentiation, apoptosis, immune system and signalling processes [17] have been reported. Anti-proliferative effects of $1,25(\mathrm{OH})_{2} \mathrm{D}$ have been demonstrated in a wide variety of cancer cell lines, including those from prostate, breast, and colon [18]. Furthermore, several studies using chromatin immunoprecipitation combined with high throughput sequencing (ChIP Seq) have reported more than 20,000 genomic VDR binding sites in different human cell lines [19-22]. Many of these are not overlapping, indicating a cell type specific effect of vitamin D. Those studies enable an insight into the diversity and impact of vitamin D on the human transcriptome. Despite the limited knowledge about the effect of vitamin D on the transcriptome, studies analyzing the gene expression in humans in intervention studies are sparse. To our knowledge there is so far only one pilot study, an RCT 
including eight subjects where the effects of supplementation with vitamin D 400 IU versus 2,000 IU daily for 2 months during the winter were compared on transcriptomic level [23].

The objective of our study was therefore to determine the effect of vitamin D supplementation on the global transcriptomic profile in a larger number of study participants who had received weekly supplementation with 20,000 IU vitamin $\mathrm{D}_{3}$ or placebo over a long period. 


\section{Material and Methods}

\subsection{Design of the study}

The subjects included in the present study all participated in the RCT "Prevention of type 2 diabetes with vitamin D supplementation in subjects with reduced glucose tolerance" that was performed from March 2008 till May 2015. The design of the main study has been described in detail before [24, 25].

In short, subjects with impaired fasting glucose (IFG) (serum glucose $6.0-6.9 \mathrm{mmol} / \mathrm{L}$ ) and/or impaired glucose tolerance (IGT) (fasting serum glucose $<7.0 \mathrm{mmol} / \mathrm{L}$ and 2-hour value $7.8-11.0$ $\mathrm{mmol} / \mathrm{L}$ at oral glucose tolerance test (OGTT) with 75 g glucose) were included. Subjects with primary hyperparathyroidism, granulomatous disease, history of urolithiasis, cancer diagnosed in the past five years, unstable angina pectoris, myocardial infarction or stroke in the past year were excluded. Pregnant or lactating women, or women of fertile age with no use of contraception, were not included.

All visits were performed at the Clinical Research Unit at the University Hospital of North Norway. Fasting blood samples and OGTT were performed annually for a period of five years. Height and weight were measured wearing light clothing. At the first visit the subjects were randomized (nonstratified) in a 1:1 ratio to one capsule vitamin D (cholecalciferol 20,000 IU (Dekristol; Mibe, Jena, Germany)) per week or an identical looking placebo capsule containing arachis oil (Hasco-Lek, Wroclaw, Poland). New medication was supplied every sixth month and unused capsules returned and counted. The subjects were not allowed to take vitamin D supplements (including cod liver oil) exceeding 400 IU per day.

If at the annual OGTT the fasting blood glucose was $>6.9 \mathrm{mmol} / \mathrm{L}$ and/or the 2 -h value $>11.0 \mathrm{mmol} / \mathrm{L}$ the subject was considered to have T2DM, thus ending their participation in the study, and thereafter retested (if necessary) and followed by their general practitioner. From November $2012 \mathrm{HbA1c} \geq 6.5$ \% was also included as an additional/alternative diagnostic criterion in accordance with the WHO report from 2011. In addition, if diagnosed elsewhere with T2DM between visits in the study, participation was terminated. As part of the safety monitoring, serum calcium levels were checked at each six months visit.

Subjects who developed persistent hypercalcemia (serum calcium $>2.55 \mathrm{mmol} / \mathrm{L}$ ), and subjects who developed renal stones, or symptoms compatible with renal stones were excluded from the study. One subject in the vitamin D group had a serum calcium levels of 2.63 and $2.64 \mathrm{mmol} / \mathrm{L}$ at two time points and was therefore excluded from the study. Two subjects in the vitamin D group and one in the placebo group had serum calcium values in the range $2.56-2.61 \mathrm{mmol} / \mathrm{L}$ that normalized at second testing, hence the subjects continued in the study. In the initial protocol, subjects who during the study were diagnosed with cancer, coronary infarction, unstable angina pectoris, or stroke, were excluded 
from the study too. From October 2011 this was changed to exclusion of subjects who during the study developed serious disease making it difficult or impossible to attend scheduled visits.

For the present study, subjects who were to come to an annual visit were informed by letter about the sub-study with the consent form enclosed. At the visit they were asked if they wanted to participate, and if so, signed the consent form. In addition, fasting blood samples were drawn in PAXgene Blood RNA tubes (PreAnalytiX), which provide immediate stabilization of intracellular RNA, for later determination of RNA expression. The samples were stored at $-70^{\circ} \mathrm{C}$ until RNA isolation and analysis at the end of the present sub-study.

To keep all investigators blinded, all data were sent directly to the Hospital's Research Department were the data files were merged and coupled to the randomization code. The Research Department then sent the final file without person identification to the principal investigator (R.J.).

The study was approved by the Norwegian Medicines Agency (EUDRACTNR - 2007-002167-27) and by the Regional Committee for Medical Research Ethics (REK NORD 2012/626). The trial is registered at ClinicalTrials.gov (NCT01771380).

\subsection{Analysis}

Serum samples for determination of 25(OH)D were frozen until analyzed in batch by an in-house LCMS/MS at the Department of Medical Biochemistry, University Hospital of North Norway [24].

\subsection{RNA preparations}

Total RNA was isolated from whole blood using the PAXgene Blood RNA Isolation system (Qiagen), and according to the manufacturer's protocol (Qiagen). RNA quantity and purity was assessed by using the NanoDrop ND-1000 spectrophotometer (ThermoFisher Scientific, Wilmington, Delaware, USA). The Experion automated electrophoresis system (BioRad, Hercules, CA, USA) and the RNA StdSens Analysis Kit was used to evaluate RNA integrity, according to the instruction manual. RNA samples were kept at $-70^{\circ} \mathrm{C}$ until further use. RNA samples with RIN $>1.8$ were used for further analysis.

\subsection{Gene Expression Analysis}

mRNA gene expression was analyzed at a certified Illumina platform at NTNU Genomics Core Facility, Trondheim, Norway. Briefly, RNA was amplified with Ambion`s Illumina ${ }^{\circledR}$ TotalPrep RNA amplification kit (Cat \#AMIL 1791) using 150 ng of total RNA as input material. Incorporation of 
biotin-labeled nucleotides was performed overnight (14 hours) at $37{ }^{\circ} \mathrm{C}$ in vitro transcription (IVT)

\subsection{Statistics and Data evaluation}

Comparisons between the groups were performed with Student's t-test or chi-square test $(\mathrm{p}<0.05)$.

Microarray data analysis was performed using the freely available software R (r-project.org). Raw files where quantile normalized including variance stabilization and background correction using the Bioconductor lumi package (Bioconductor.org). Probes were mapped to gene symbol and genome position using the Bioconductor illuminaHumanv4.db package (http://bioconductor.org/packages/release/data/annotation/html/illuminaHumanv4.db.html). Probes with a log2 expression below 7 were removed from the dataset, as the expression level was considered too low to discriminate from background. Descriptive statistics using STATA MP13, were used for comparison of participant groups. Gene expression differences between comparison groups were analyzed using the Limma package (Bioconductor.org). Differentially expressed genes were tested for over-represented pathways with the GO hyperGTest algorithm in Kegg ("http://bioconductor.org/packages/release/bioc/html/clusterProfiler.html"). The data are deposited and $\begin{array}{lllll}\text { accepted in } & \text { GEO under accession number }\end{array}$ (https://www.ncbi.nlm.nih.gov/geo/query/acc.cgi?acc=GSE94138).

Enriched genesets were created using Limma differentially regulated probes as input to the Bioconductor GOstats hyperGTest function. Enriched genesets with a $\mathrm{p}<0.05$ were kept. Principal component analysis (PCA) and Partial least squares regression (PLS) [26] were applied on the data in order to visualize the data structure and look for potential outlier samples (https://cran.rproject.org/web/packages/mixOmics/index.html). Gene Set Enrichment Analysis (GSEA) was performed using the R statistical package (http://www.broad.mit.edu/gsea/). Gene Set Enrichment Analysis (GSEA) is a computational method that determines whether an defined set of genes shows statistically significant, concordant differences between two biological states [27]. PANTHER (Protein Analysis through Evolutionary Relationships) Classification System version 10.0 (http://pantherdb.org/) was used for pathway analysis and to classify regulated genes according to their biological function ( $<<0.05$ was considered statistically significant). PANTHER is designed to classify proteins and their genes in order to facilitate high-throughput analysis [28]. 
1

2

3

4

5

9

10

11

12

13

14

15

16

17

18

19

20

21

22

23

24

25

26

27

28

29

30

31

32

33

34

35

36

37

38

39

40

41

42

43

44

45

46

47

48

49

50

51

52

53

54

55

56

57

58

59

60

61

62

63

64

65 


\section{Results and discussion}

\subsection{Background variables}

For the present sub-study, 115 subjects were invited and 94 accepted the invitation, 47 in the vitamin $\mathrm{D}$ group and 47 in the placebo group.

The two groups did not differ significantly in terms of gender, age, BMI and duration of intervention. There were more smokers among the vitamin D group, but the difference was not statistically significant. At inclusion in the main study the mean serum 25(OH)D levels were similar and as expected, at inclusion in the present sub-study the mean serum 25(OH)D levels were significantly higher in the vitamin D group than the placebo group $(119.4 \pm 29.1 \mathrm{nmol} / \mathrm{L}$ versus $63.4 \pm 18.6 \mathrm{nmol} / \mathrm{L}$ $(\mathrm{p}<0.001)$ (Table 1).

Table 1: Background data of the study participants ( $\mathrm{n}=94)$

\begin{tabular}{|c|c|c|c|c|c|c|}
\hline & \multicolumn{3}{|c|}{ Vitamin D group } & \multicolumn{3}{|c|}{ Placebo group } \\
\hline & $\begin{array}{l}\text { All } \\
n=47\end{array}$ & $\begin{array}{l}\text { Men } \\
n=29\end{array}$ & $\begin{array}{l}\text { Women } \\
n=18\end{array}$ & $\begin{array}{l}\text { All } \\
n=47\end{array}$ & $\begin{array}{l}\text { Men } \\
\mathbf{n}=35\end{array}$ & $\begin{array}{l}\text { Women } \\
\mathbf{n}=12\end{array}$ \\
\hline Women/Men [\%] & $38.3 / 61.7$ & $0 / 100$ & $100 / 0$ & $25.5 / 74.5$ & $0 / 100$ & $100 / 0$ \\
\hline $\begin{array}{l}\text { Age at inclusion in present } \\
\text { sub-study [years] }\end{array}$ & $\begin{array}{l}61.0 \\
( \pm 8.5)\end{array}$ & $\begin{array}{l}61.0 \\
( \pm 7.7)\end{array}$ & $\begin{array}{l}61.1 \\
( \pm 9.9)\end{array}$ & $\begin{array}{l}62.3 \\
( \pm 8.6)\end{array}$ & $\begin{array}{l}61.0 \\
( \pm 8.1)\end{array}$ & $\begin{array}{l}65.8 \\
( \pm 9.4)\end{array}$ \\
\hline $\begin{array}{l}\text { BMI at inclusion in present } \\
\text { sub-study }\left[\mathrm{kg} / \mathrm{m}^{2}\right]\end{array}$ & $\begin{array}{l}29.0 \\
( \pm 3.8)\end{array}$ & $\begin{array}{l}28.8 \\
( \pm 3.8)\end{array}$ & $\begin{array}{l}29.3 \\
( \pm 3.9)\end{array}$ & $\begin{array}{l}28.90 \\
( \pm 3.9)\end{array}$ & $\begin{array}{l}29.5 \\
( \pm 3.0)\end{array}$ & $\begin{array}{l}27.1 \\
( \pm 5.4)\end{array}$ \\
\hline $\begin{array}{l}\text { Duration of intervention } \\
\text { [month] }\end{array}$ & $\begin{array}{l}50.6 \\
( \pm 8.4)\end{array}$ & $\begin{array}{l}49.1 \\
( \pm 9.5)\end{array}$ & $\begin{array}{l}52.9 \\
( \pm 5.9)\end{array}$ & $\begin{array}{l}49.8 \\
( \pm 9.7)\end{array}$ & $\begin{array}{l}47.4 \\
( \pm 9.8)\end{array}$ & $\begin{array}{l}56.7 \\
( \pm 5.5)\end{array}$ \\
\hline $\begin{array}{l}\text { Serum } 25(\mathrm{OH}) \mathrm{D} \text { at inclusion } \\
\text { in main study [nmol/L] }\end{array}$ & $\begin{array}{l}61.4 \\
( \pm 27.4)\end{array}$ & $\begin{array}{l}61.4 \\
( \pm 31.3)\end{array}$ & $\begin{array}{l}61.5 \\
( \pm 20.4)\end{array}$ & $\begin{array}{l}61.9 \\
( \pm 19.2)\end{array}$ & $\begin{array}{l}59.4 \\
( \pm 16.3)\end{array}$ & $\begin{array}{l}69.1 \\
( \pm 25.3)\end{array}$ \\
\hline $\begin{array}{l}\text { Serum } 25(\mathrm{OH}) \mathrm{D} \text { at inclusion } \\
\text { in present sub-study [nmol/L] }\end{array}$ & $\begin{array}{l}119.5^{*} \\
( \pm 29.1)\end{array}$ & $\begin{array}{l}119.6 * * \\
( \pm 28.7)\end{array}$ & $\begin{array}{l}119.3^{* * *} \\
( \pm 30.6)\end{array}$ & $\begin{array}{l}63.4^{*} \\
( \pm 18.6)\end{array}$ & $\begin{array}{l}62.6 * * \\
( \pm 19.9)\end{array}$ & $\begin{array}{l}65.7 * * * \\
( \pm 14.8)\end{array}$ \\
\hline $\begin{array}{l}\text { Smoking status at inclusion in } \\
\text { present sub-study [\%] }\end{array}$ & 21.3 & 20.7 & 22.2 & 8.5 & 5.7 & 16.7 \\
\hline
\end{tabular}

$*, * *, * * *$ Student's t-test $(\mathrm{p}<0.01)$

\subsection{Gene expression levels in the two study groups}

The clinical trial included pre-diabetic subjects, but there was no effect on the gene expression in terms of different HbA1c levels of the patients (data not shown). This goes along with the previously published results of the main study, which did not show a protective effect of vitamin D supplementation on the onset of type 2 diabetes $[24,25]$. Multivariate data analysis were performed in order to quality assure the gene expression data, and to evaluate if the data were able to separate 
between subjects receiving vitamin $\mathrm{D}$ and those receiving placebo. In a principal component analysis (PCA) women and men could be separated upon their gene expression but no major grouping of the two study groups (vitamin D and placebo) was visible. A partial least square regression analysis (PLS) using serum 25(OH)D levels revealed no further separation between the two groups (data not shown). Although no clear grouping effects were seen, when looking at individual genes, 141 were found to be regulated by vitamin $\mathrm{D}(\mathrm{p}<0.05)$ with log2 fold changes between $|0.04|$ and $|0.40|$. In order to quality assure the data we filtered for genes with a log2 fold change of minimum $|0.2|$, which resulted in five downregulated genes: Formyl peptide receptor 2 (FPR2), CD52 molecule (CD52), interleukin 1 receptor type 2 (IL1R2), G protein subunit gamma 10 (GNG10) and folate receptor 3 gamma (FOLR3). Ribosomal protein S26 (RPS26) was the only upregulated gene. Out of these six genes significantly changed between the vitamin $\mathrm{D}$ and the placebo group, only two are to our knowledge published previously as regulated in context with vitamin D (GNG10 [29, 30] and RPS26 [31]). All other regulated genes we found had a log2 fold change of less than $|0.2|$. Nevertheless could also small changes in gene expression have profound physiological effects. One explanation for the low number of regulated genes could be the high baseline serum 25(OH)D levels in both study groups $(\sim 61$ $\mathrm{nmol} / \mathrm{L}$ ), which indicated that the subjects at inclusion already had a sufficient serum 25(OH)D level, hence a benefit of additional supplementation might be rather unlikely. Furthermore, we were comparing the mRNA levels of two study groups with each other and not the personal change of each subject due to vitamin D supplementation since we just had one sample of each person after long time intervention and not at baseline. This could yield reduced statistical power and leave individual changes undetected. Another explanation could be the long intervention time, which could reduce the prominence of the gene expression response to vitamin D supplementation. Additionally, detecting small changes in the mRNA is challenging with microarrays, and might be especially so in blood, as its composition is underlying very fast changes and is sensitive to all kind of environmental changes [32].

\subsubsection{Effect of gender}

Next, we analyzed women and men separately in order to explore if gender could influence the effect of vitamin D on global gene expression. Male participants of both study groups did not separate in either PCA or PLS (Figure 1A and 1B), but there was a grouping for female participants in PCA (Figure 1C) which became more obvious when looking at the corresponding PLS (Figure 1D). For the PLS plots the serum 25(OH)D levels were used as the scoring criteria. The plots indicated an effect of the 25(OH)D level for both men and women, as participants with lower 25(OH)D levels often grouped together with the placebo group, while participants with high 25(OH)D levels grouped separately. It is important to mention, that the female or male vitamin D group did not differ significantly from the corresponding placebo group in terms of physiological characteristics other than serum 25(OH)D level at inclusion in the sub-study (Table 1). 

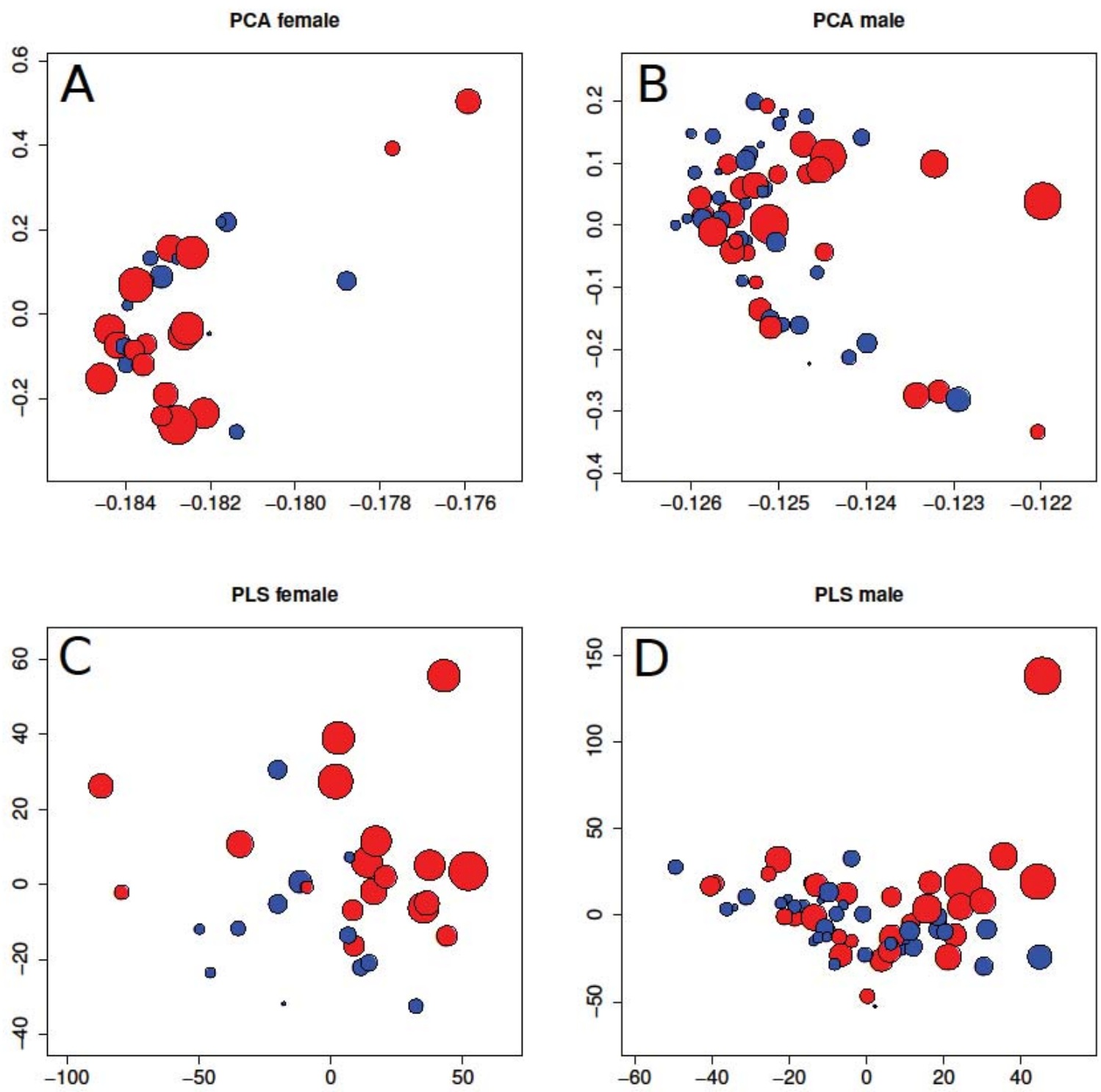

Figure 1: Multivariate data analysis of microarray data from subject after vitamin D (red) or placebo (blue) supplementation. The size of the data spots correlates with the 25(OH)D level. (A) PCA women, (B) PCA men, (C) PLS regression women, and (D) PLS regression men. 25(OH)D level was used as the scoring vector for PLS analysis. In both female and male PCA, principle component 1 (PC1) accounted for more than 90\% of explained variance.

In sum, 58 genes were regulated in men but 3.2 times more $(n=185)$ in women $(p<0.05)$ (supplementary information). After filtering with a log2 fold change of minimum |0.2|, one gene remained regulated in men (interleukin 1 receptor, type II) while 51 remained regulated in women (Tables S2 and S3, supplementary information). Hereby, we could detect for the first time a stronger effect of vitamin D supplementation on gene expression in women when compared to men. An explanation for the differences between women and men might be the in general different serum DBP level between the genders [33], caused most probably by an estrogen-dependent DBP synthesis [34]. Hence, women have higher DBP concentrations and higher serum 25(OH)D concentrations [35] and 
when embracing also our findings, we assume a possible more important role of vitamin D or more

The GSEA of the female data set indicated a major effect of vitamin D supplementation on the immune system, but also on the establishment and/or maintenance of the chromatin architecture, transcription coactivator activity, microtubule cytoskeleton and phosphatidylinositol signaling system (Table S3, supplementary information).

In sum, 51 vitamin $\mathrm{D}$ dependent regulated genes in women could be identified ( $\mathrm{p}<0.05$, log2 fold change $\geq|0.2|$ ) of which 38 have to our knowledge not been reported before as regulated upon vitamin D supplementation and thus are interesting for further research on the effect of vitamin D in the human body. For example, the Fas apoptotic inhibitory molecule 3 (FAIM3) was upregulated upon vitamin D supplementation in women. FAIM3 is playing an important role in inflammatory autoimmune responses and protects against death receptor-induced apoptosis by modulating the receptors function [36]. Another example is the observed downregulation of Charcot-Leyden crystal galectin (CLC). This gene is expressed in a variety of tissues and body fluids and is a known marker for allergic inflammation in asthma and allergic rhinitis. However, the role and function of CLC is not entirely understood [37].

\subsubsection{Effect of serum 25(OH)D level for detection of vitamin D dependent changes}

In another sub-analysis we wanted to investigate if focusing on the subjects with the lowest versus subjects with the highest serum 25(OH)D levels would reveal further effects on the gene expression. For this analysis we included the 20 participants with the lowest ("Bottom 20", serum 25(OH)D 27 - 
$59 \mathrm{nmol} / \mathrm{L}$ ) and the 20 participants with the highest ("Top 20", serum 25(OH)D $122-204 \mathrm{nmol} / \mathrm{L}$ ) serum 25(OH)D level at inclusion in this sub-study. This number was chosen, as all subjects in the Bottom 20 group received placebo and the group's average 25(OH)D level is insufficient according to the Institute of Medicine [38], while all subjects in the Top 20 group received vitamin D.

Analysis of the background data revealed no significant differences between the study groups except their serum 25(OH)D levels at inclusion in the present sub-study (Table 3).

Table 3: Background data of the study participants ( $\mathrm{n}=40)$ with Bottom 20 and Top 20 serum 25(OH)D levels

\begin{tabular}{|c|c|c|}
\hline & Bottom 20 & Top 20 \\
\hline Women/Men [\%] & $15 / 85$ & $40 / 60$ \\
\hline $\begin{array}{l}\text { Age at inclusion in present sub-study } \\
\text { [years] }\end{array}$ & $61( \pm 10)$ & $63( \pm 9.2)$ \\
\hline $\begin{array}{l}\text { BMI at inclusion in present sub- } \\
\text { study }\left[\mathrm{kg} / \mathrm{m}^{2}\right]\end{array}$ & $34.3( \pm 2.7)$ & $36.1( \pm 4.7)$ \\
\hline Duration of intervention [month] & $50.6( \pm 9.6)$ & $51.5( \pm 7.8)$ \\
\hline $\begin{array}{l}\text { Serum } 25(\mathrm{OH}) \mathrm{D} \text { at inclusion in main } \\
\text { study [nmol/L] }\end{array}$ & $54.4( \pm 14.3)$ & $67.9( \pm 36.6)$ \\
\hline $\begin{array}{l}\text { Serum } 25(\mathrm{OH}) \mathrm{D} \text { at inclusion in } \\
\text { present sub-study }[\mathrm{nmol} / \mathrm{L}]\end{array}$ & $47.4( \pm 10.6)^{*}$ & $145.4( \pm 22.1)^{*}$ \\
\hline $\begin{array}{l}\text { Smoking at inclusion in present sub- } \\
\text { study [\%] }\end{array}$ & 10 & 30 \\
\hline
\end{tabular}

Interestingly, the expression of 198 mRNAs was differently regulated between these two groups $(\mathrm{p}<0.05)$ (supplementary information). This nearly seven times increase compared to the analysis of all 94 subjects supports the hypothesis that a vitamin D threshold exists, above which additional supplementation may not have a major effect [38]. PLS analysis showed clustering of the two study groups (Figure 2), which could not be observed previously when considering all 94 patients (as mentioned in 3.2). 


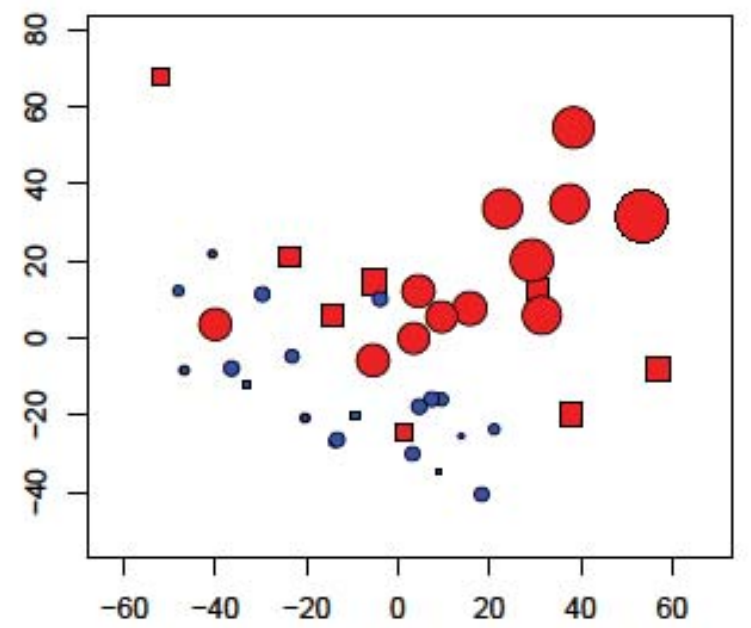

Figure 2: Partial-least-square regression analysis of the gene expression data of the 20 subject with the highest 25(OH)D level after vitamin D supplementation (red) and the 20 subject with the lowest 25(OH)D level after placebo supplementation (blue). The size of the data spots correlates with the 25(OH)D level. Circles represent female participants and squares male participants. Serum 25(OH)D level was used as the PLS scoring vector.

For further evaluation, we filtered the data with a log2 fold change of minimum $|0.2|$ and used the resulting 41 genes (Figure S4 and S5, supplementary information) for analysis of pathways and biological processes (Table 4). To our knowledge, 30 of these genes have not been published before in gene expression studies after vitamin D intervention. As an example, ornithine decarboxylase antizyme 1 (OAZ1) was upregulated in participants with high serum 25(OH)D levels. It has been recently reported that OAZ1 display tumor suppressor activities and has anti-proliferative effects, and influences on cell differentiation and apoptosis [26]. As another example, Granzyme H (GZMH) was downregulated in those with high serum 25(OH)D. Granzymes have different proteolytic specificities and are potentially able to initiate cell death in tumor and virally infected cells, but so far the biologic functions of GZMH in immune defense cells is hardly understood. In recent studies a high level of GZMH has been found in natural killer cells [39].

Functional analysis of the regulated genes could reveal an influence of vitamin D on three different pathways: oxidative stress response, apoptosis signaling pathway and gonadotropin releasing hormone receptor. Oxidative stress and defective apoptotic processes have been related to several severe diseases in humans like cancer, autoimmune and inflammatory diseases. An influence of vitamin D on both pathways has been implied [40-43], but its role is not fully understood.

Gonadotropin releasing hormone receptor plays a major role in controlling the follicular growth, ovulation, corpus luteum maintenance and spermatogenesis, and has been found in cancers of the 
reproduction system like breast, ovary, endometrium and prostate [44]. In that context it is interesting

\begin{tabular}{|c|c|c|c|c|}
\hline & Hits & $\begin{array}{l}\text { Expected } \\
\text { Hits }\end{array}$ & $\begin{array}{l}\text { Fold } \\
\text { Enrichment }\end{array}$ & P-value \\
\hline \multicolumn{5}{|l|}{ PANTHER Pathways } \\
\hline Oxidative stress response (P00046) & 1 & 0.05 & $>5$ & 4.81E-02 \\
\hline Apoptosis signaling pathway (P00006) & 2 & 0.21 & $>5$ & $1.88 \mathrm{E}-02$ \\
\hline $\begin{array}{l}\text { Gonadotropin releasing hormone receptor } \\
\text { pathway (P06664) }\end{array}$ & 3 & 0.41 & $>5$ & 8.04E-03 \\
\hline \multicolumn{5}{|l|}{ PANTHER GO-Slim Biological Process } \\
\hline Protein methylation (GO:0006479) & 1 & 0.03 & $>5$ & 2.52E-02 \\
\hline $\begin{array}{l}\text { Negative regulation of apoptotic process } \\
\text { (GO:0043066) }\end{array}$ & 2 & 0.17 & $>5$ & $1.31 \mathrm{E}-02$ \\
\hline Natural killer cell activation (GO:0030101) & 2 & 0.18 & $>5$ & $1.42 \mathrm{E}-02$ \\
\hline B cell mediated immunity (GO:0019724) & 2 & 0.26 & $>5$ & 2.75E-02 \\
\hline $\begin{array}{l}\text { Regulation of phosphate metabolic process } \\
\text { (GO:0019220) }\end{array}$ & 2 & 0.32 & $>5$ & 4.20E-02 \\
\hline Immune response (GO:0006955) & 5 & 0.95 & $>5$ & 2.42E-03 \\
\hline Translation (GO:0006412) & 4 & 0.79 & $>5$ & 7.99E-03 \\
\hline Immune system process (GO:0002376) & 11 & 2.54 & 4.33 & 2.62E-05 \\
\hline Apoptotic process (GO:0006915) & 4 & 1 & 4 & $1.74 \mathrm{E}-02$ \\
\hline Cell death (GO:0008219) & 4 & 1.03 & 3.9 & 1.89E-02 \\
\hline Death (GO:0016265) & 4 & 1.03 & 3.87 & 1.93E-02 \\
\hline Response to stimulus (GO:0050896) & 12 & 3.96 & 3.03 & 3.29E-04 \\
\hline Protein metabolic process (GO:0019538) & 11 & 4.91 & 2.24 & 7.11E-03 \\
\hline $\begin{array}{l}\text { Regulation of biological process } \\
\text { (GO:0050789) }\end{array}$ & 10 & 5.2 & 1.92 & 2.83E-02 \\
\hline
\end{tabular}

In summary, we performed gene expression analysis of whole blood samples from 94 participants with prediabetes after supplementation with vitamin D or placebo. The method of testing transcriptomic differences in whole blood does not take tissue specific actions of vitamin D into account, but has the advantage of using peripheral blood as an easily accessible surrogate tissue. The method thereby is of importance to detect and analyze the effects of vitamin D on pathways and biological processes, and could be used to develop and apply a biomarker detection platform. The samples were drawn during a five years lasting RCT with the main goal to evaluate the influence of vitamin D on glucose metabolism and development of type 2 diabetes. At the time of publication, these results were by far the largest RCT on vitamin D supplementation in individuals with prediabetes [24, 25], and also our gene expression analysis is as of today the largest conducted after vitamin D supplementation in humans. 
We could not separate the vitamin D receiving group form the placebo group with PCA and PLS analysis when all 94 study participants were taken into consideration. Indeed, there were just five mRNAs down-regulated and one up-regulated in the vitamin D group compared to the placebo group ( $<<0.05, \log 2$ fold change $\geq|0.2|$ ). However, sub-group analysis could reveal an effect of vitamin $\mathrm{D}$ on the gene expression in humans, which was stronger in women than in men, and also more evident when separately evaluating the subjects with the lowest versus the highest serum 25(OH)D levels. A total number of 99 gene $(p<0.05$, log2 fold change $\geq|0.2|)$ were found to be regulated by vitamin $\mathrm{D}$, out of which 72 have not been published before. However, since these effects were only seen in sub-group analysis of the pre-diabetic study population, they will be subjects for future studies.

In particular, vitamin D showed an influence on the interleukin signaling pathway, oxidative stress response, apoptosis signaling pathway and gonadotropin releasing hormone receptor pathway. In addition, on genes involved in regulation of sequence-specific DNA binding transcription factor activity, hemopoiesis, B cell mediated immunity and regulation of translation, as well as the immune system, establishment and/or maintenance of the chromatin architecture, transcription coactivator activity, microtubule cytoskeleton and phosphatidylinositol signaling system.

\section{Funding}

This study was supported by grants from The North Norway Regional Health Authority, The Norwegian Diabetes Association, The University of Tromsø, The Research Council of Norway, and The Novo Nordisk foundation.

The authors have declared no conflict of interests. 


\section{References}

1. Bikle, D.D., Vitamin D and bone. Curr Osteoporos Rep, 2012. 10(2): p. 151-9.

2. Adams, J.S. and M. Hewison, Update in vitamin D. J Clin Endocrinol Metab, 2010. 95(2): p. 471-8.

3. Rosen, C.J., et al., The nonskeletal effects of vitamin D: an Endocrine Society scientific statement. Endocr Rev, 2012. 33(3): p. 456-92.

4. Jorde, R., et al., Effects of vitamin D supplementation on symptoms of depression in overweight and obese subjects: randomized double blind trial. J Intern Med, 2008. 264(6): p. 599-609.

5. Konradsen, S., et al., Serum 1,25-dihydroxy vitamin D is inversely associated with body mass index. Eur J Nutr, 2008. 47(2): p. 87-91.

6. Schottker, B., et al., Vitamin D and mortality: meta-analysis of individual participant data from a large consortium of cohort studies from Europe and the United States. BMJ, 2014. 348: p. g3656.

7. Vimaleswaran, K.S., et al., Association of vitamin D status with arterial blood pressure and hypertension risk: a mendelian randomisation study. Lancet Diabetes Endocrinol, 2014. 2(9): p. 719-29.

8. Jorde, R. and G. Grimnes, Vitamin D and health: the need for more randomized controlled trials. J Steroid Biochem Mol Biol, 2015. 148: p. 269-74.

9. van Schoor, N.M. and P. Lips, Worldwide vitamin D status. Best Pract Res Clin Endocrinol Metab, 2011. 25(4): p. 671-80.

10. Holick, M.F., Vitamin D deficiency. N Engl J Med, 2007. 357(3): p. 266-81.

11. Cashman, K.D., et al., Vitamin D deficiency in Europe: pandemic? Am J Clin Nutr, 2016.

12. Didriksen, A., et al., The serum 25 -hydroxyvitamin $D$ response to vitamin $D$ supplementation is related to genetic factors, BMI, and baseline levels. Eur J Endocrinol, 2013. 169(5): p. 559-67.

13. Carlberg, C., Genome-wide (over)view on the actions of vitamin D. Front Physiol, 2014. 5: p. 167.

14. Bouillon, R., et al., Vitamin D and human health: lessons from vitamin D receptor null mice. Endocr Rev, 2008. 29(6): p. 726-76.

15. Ramagopalan, S.V., et al., A ChIP-seq defined genome-wide map of vitamin D receptor binding: associations with disease and evolution. Genome Res, 2010. 20(10): p. 1352-60.

16. Yen, P.M., et al., Vitamin D receptors repress basal transcription and exert dominant negative activity on triiodothyronine-mediated transcriptional activity. J Biol Chem, 1996. 271(18): p. 10910-6.

17. Savli, H., et al., Gene expression analysis of 1,25(OH)2D3-dependent differentiation of HL-60 cells: a cDNA array study. Br J Haematol, 2002. 118(4): p. 1065-70.

18. Campbell, M.J., Vitamin D and the RNA transcriptome: more than mRNA regulation. Front Physiol, 2014. 5: p. 181.

19. Tuoresmaki, P., et al., Patterns of genome-wide VDR locations. PLoS One, 2014. 9(4): p. e96105.

20. Goeman, F., et al., VDR primary targets by genome-wide transcriptional profiling. J Steroid Biochem Mol Biol, 2014. 143: p. 348-56.

21. Seuter, S., A. Neme, and C. Carlberg, Characterization of genomic vitamin D receptor binding sites through chromatin looping and opening. PLoS One, 2014. 9(4): p. e96184.

22. Heikkinen, S., et al., Nuclear hormone 1alpha,25-dihydroxyvitamin D3 elicits a genome-wide shift in the locations of VDR chromatin occupancy. Nucleic Acids Res, 2011. 39(21): p. 918193.

23. Hossein-nezhad, A., A. Spira, and M.F. Holick, Influence of vitamin D status and vitamin D3 supplementation on genome wide expression of white blood cells: a randomized double-blind clinical trial. PLoS One, 2013. 8(3): p. e58725.

24. Jorde, R., et al., Vitamin D 20,000 IU per Week for Five Years Does Not Prevent Progression From Prediabetes to Diabetes. J Clin Endocrinol Metab, 2016. 101(4): p. 1647-55. 
25. Sollid, S.T., et al., No effect of high-dose vitamin D supplementation on glycemic status or

26. Tenenhaus, M., La régression PLS : théorie et pratique. 1998, Paris: Editions Technip. x, 254 p.

27. Subramanian, A., et al., Gene set enrichment analysis: a knowledge-based approach for interpreting genome-wide expression profiles. Proc Natl Acad Sci U S A, 2005. 102(43): $p$. 15545-50.

28. Thomas, P.D., et al., PANTHER: a library of protein families and subfamilies indexed by function. Genome Res, 2003. 13(9): p. 2129-41.

29. Baeke, F., et al., The vitamin D analog, TX527, promotes a human CD4+CD25highCD127low regulatory $T$ cell profile and induces a migratory signature specific for homing to sites of inflammation. J Immunol, 2011. 186(1): p. 132-42.

30. Stuckey, A., et al., Integrated genomics of ovarian xenograft tumor progression and chemotherapy response. BMC Cancer, 2011. 11: p. 308.

31. Riek, A.E., J. Oh, and C. Bernal-Mizrachi, Vitamin D regulates macrophage cholesterol metabolism in diabetes. J Steroid Biochem Mol Biol, 2010. 121(1-2): p. 430-3.

32. Dumeaux, V., et al., Deciphering normal blood gene expression variation--The NOWAC postgenome study. PLoS Genet, 2010. 6(3): p. e1000873.

33. Bolland, M.J., et al., Age-, gender-, and weight-related effects on levels of 25-hydroxyvitamin $D$ are not mediated by vitamin D binding protein. Clin Endocrinol (Oxf), 2007. 67(2): p. 25964.

34. Speeckaert, M., et al., Biological and clinical aspects of the vitamin D binding protein (Gcglobulin) and its polymorphism. Clin Chim Acta, 2006. 372(1-2): p. 33-42.

35. Hagenau, T., et al., Global vitamin D levels in relation to age, gender, skin pigmentation and latitude: an ecologic meta-regression analysis. Osteoporos Int, 2009. 20(1): p. 133-40.

36. Planells-Ferrer, L., et al., FAIMs: more than death-receptor antagonists in the nervous system. J Neurochem, 2016. 139(1): p. 11-21.

37. Lin, T.A., et al., The mRNA level of Charcot-Leyden crystal protein/galectin-10 is a marker for CRTH2 activation in human whole blood in vitro. Biomarkers, 2010. 15(7): p. 646-54.

38. Ross, A.C., et al., The 2011 report on dietary reference intakes for calcium and vitamin $D$ from the Institute of Medicine: what clinicians need to know. J Clin Endocrinol Metab, 2011. 96(1): p. 53-8.

39. Fellows, E., et al., Natural killer cell-derived human granzyme $\mathrm{H}$ induces an alternative, caspase-independent cell-death program. Blood, 2007. 110(2): p. 544-52.

40. Haas, M.J., et al., Inhibition of endoplasmic reticulum stress and oxidative stress by vitamin $D$ in endothelial cells. Free Radic Biol Med, 2016. 99: p. 1-10.

41. Gabr, S.A., et al., Correlation between vitamin D levels and apoptosis in geriatric patients infected with hepatitis C virus genotype 4. Clin Interv Aging, 2016. 11: p. 523-33.

42. Ke, C.Y., et al., Vitamin D3 Reduces Tissue Damage and Oxidative Stress Caused by Exhaustive Exercise. Int J Med Sci, 2016. 13(2): p. 147-53.

43. Tohari, A.M., X. Zhou, and X. Shu, Protection against oxidative stress by vitamin D in cone cells. Cell Biochem Funct, 2016. 34(2): p. 82-94.

44. McArdle, C.A., Gonadotropin-releasing hormone receptor signaling: biased and unbiased. Mini Rev Med Chem, 2012. 12(9): p. 841-50.

45. Lerchbaum, E. and B. Obermayer-Pietsch, Vitamin D and fertility: a systematic review. Eur J Endocrinol, 2012. 166(5): p. 765-78. 